\title{
Silence between patients and doctors: the issue of self-determination and amniocentesis in Japan
}

\author{
MASAE KATO ${ }^{1}$
}

\begin{abstract}
Japan is among the few countries that have passed laws concerning eugenics. Consequently, the practice of selective abortion (abortion of an abnormal foetus) has been publicly debated for the past 35 years. Nevertheless, data show that knowledge in Japan about prenatal diagnosis is anything but common. In my fieldwork (AprilJune 2006) only $38 \%$ of interviewees (13/34) knew or had heard of 'amniocentesis' and $6 \%$ knew nothing about it at all. There are many explanations for why people are unaware of prenatal diagnosis. The most crucial factor is that medical doctors do not talk to their patients about it. My interviews with 11 medical doctors revealed that they do not talk about it because they want to respect the principle of patient selfdetermination. In this paper I aim first to introduce and analyse, in the context of Japanese eugenic history and the contemporary notion of the patient-doctor relationship, medical doctors' explanations for not talking to their patients about amniocentesis. Second, I address whether the principle of 'non-intervention' equates to 'self-determination'. Lastly, I suggest possible improvements to the practice of 'self-determination' in Japan.
\end{abstract}

\section{Introduction}

Japan is among the few countries that have passed official laws on eugenics. Consequently, the practice of selective abortion (abortion of an 'abnormal' foetus) has been publicly debated for the past 35 years. My field research shows, however, that in Japan knowledge about prenatal diagnosis - even an awareness of the term itself, let alone its definition - is not widely shared: more than half (19/34) had been unaware of it prior to their pregnancy. This was contrary to expectation, as amniocentesis was introduced almost 40 years ago and society has debated the test's pros and cons since the 1970s.

Several factors explain why individuals are unaware of amniocentesis. The main one, it turns out, is that obstetricians (OBs) do not talk about amniocentesis with pregnant women (hereafter, 'patients'). The main reason why they do not, according to OBs' own reasoning, is because they believe "giving information about prenatal testing will hinder patients' practice of self-determination". I also observed that some doctors do not provide enough support to patients in their decision-making; instead, they say, they let patients 'self-determine'.

Why is 'non-intervention' equated with 'self-determination'? Is it a theoretical misreading? If so, how and why? What does the term actually mean? These sensitive problems - 'sensitive' in that the concept of 'self-determination' and related ideas are 
easily misunderstood when discussed only at the theoretical level - need to be considered in the concrete context of medical practice.

In this paper, I address these questions by analysing $\mathrm{OB}$ and patient narratives and by elucidating characteristics of the patient-doctor relationship in Japan, an important context in which to consider the meaning of 'self-determination'. By doing so, I expect to contribute to the theoretical and practical understanding of the principle of 'self-determination' and of how and why the gap between theory and practice exists. I also expect to suggest improvements to the practice of 'self-determination' in Japan.

\section{Target group}

I collected 34 narratives from female patients during one- to two-hour semi-structured interviews in Japan between April and June 2006. Interviewees were either pregnant, or had been pregnant during the past ten years. I came into contact with them mainly through my personal networks: introduction by handicapped people's groups, women's groups, OBs, and acquaintances. They were located in Tokyo (11/34), suburbs of Tokyo (11/34), Osaka (2/34), the North East area (6/34) and the West area (3/34) of Japan. Four were currently pregnant. Seventeen of the $34(50 \%)$ had graduated from high school as the last educational record; seven $(21 \%)$ had graduated from either junior college or high vocational school; eight (24\%) held a bachelor's degree; two $(6 \%)$ held a master's degree. This proportion is not significantly different from the educational composition of Japan as a whole: according to figures issued by the Ministry of Education in Japan: in 2005, 47.3\% were graduates of university, junior college or high vocational school, and $97.3 \%$ went to high school. ${ }^{2}$

I interviewed 11 OBs: nine were amniocentesis specialists, one was an ultrasound specialist and one was a specialist in infertility treatments. All but one were specialists in prenatal diagnosis, who were able to talk about not only their own medical practice but the situation in wider Japanese society. One was specialised in sexually transmitted diseases. I interviewed this OB in order to explore how a non-specialist in prenatal diagnosis deals with the issue in her medical practice.

\section{An analysis of $\mathrm{OB}$ narratives}

Why do OBs not actively disseminate information about amniocentesis? The most frequent explanation, offered by eight of the eleven OBs, was that they do not want to "force" or "guide" patients to take the test. According to Dr E:

If OBs tell patients that they can take amniocentesis because they are at advanced ages, I am sure that they feel forced into it. Therefore, I do not mention it myself.

Similarly, Dr A says:

I only ask them when there is any anxiety because of their age, when a pregnant woman is older than 35. I do not want to force them. 
These quotations (emphases by the author) show how OBs fear that the mere mention of amniocentesis might be interpreted by patients as a recommendation or even an imposition. This is a widely shared opinion among medical doctors, and it is even recognised as fact in government literature: one of the guidelines from the Ministry of Health, Welfare and Labour (MHWL) for administering blood marker tests, for example, advises doctors "to support pregnant women because it is difficult for them to go against what a doctor says". 3

Then why should an OB's mere mention of amniocentesis sound to patients like a recommendation? The answer to this question provides perspective on the patientdoctor relationship. An obstetrician/gynaecologist named Satô, one of Japan's most experienced in the practice of amniocentesis, argues this point from the perspective of the "gap in knowledge between a doctor and a patient". He says that "it is not possible for a patient to practise self-determination unless he or she is determined to become a professional in the medical field, because for a patient to have the same knowledge as medical doctors even only about effects and side-effects of a treatment, for example, would take at least one year". ${ }^{4}$ Providing information only during diagnosis sessions is hardly enough, and insufficient provision of information will cause anxiety among patients. The genetic counselling system is, as will be discussed later, not thoroughly established in Japan although efforts are underway to improve the situation, through the establishment of degree courses in genetic counselling at universities, for example. ${ }^{5}$ In present circumstances, however, if the OB feels the patient does not necessarily need such information, then he should not provide it in an unprepared manner. That information which is provided ought to be well considered beforehand by the doctor. ${ }^{6}$ The "gap in knowledge" plays one critical role in the patient-doctor relationship.

A doctor's knowledge makes him a professional; for patients, he is seen as much more than a mere service or provider of information. Accordingly, a doctor's words tend to be taken as absolute, and patients sometimes uncritically rely on them. It is possible to observe this tendency in $\mathrm{OB}$ and patient narratives. The statement of $\mathrm{Mr} \mathrm{Z}$, a father of two, for example, shows exactly this point. To explain why he and his wife did not consider amniocentesis, Mr Z says:

OBs are professionals in the field...I thought that there would be no mistake if I only follow what medical doctors say...Keeping our $O B$ 's words in mind, we proceeded with our two pregnancies on our own'.

OBs are aware of this attitude among their patients. According to Dr A:

Patients often believe that we medical doctors are almighty, and that if the result of amniocentesis assures that there is no problem in a foetus, some think that they might have a super baby or something.

Here, it is possible to observe that expectations of patients and OBs do not correspond. Conscious of their influence, OBs do not want to guide patients, while at the same 
time patients do not aim to decide for themselves and sometimes even wait for their $\mathrm{OB}$ to guide them. The statement of $\mathrm{Mr} \mathrm{Z}$ also shows that making decisions together with OBs (ie, "keeping our OB's words in mind,") is part of the patient's concept of the practice of self-determination (ie, "we proceeded with our two pregnancies on our own.") This differs from OB conceptions of 'self-determination'.

All the OBs associated the provision of information about the test with 'causing anxiety'. If amniocentesis is something beneficial to a patient, it should not be problematic when recommended to them. But I hypothesise that some problematic or sensitive values are attached to amniocentesis as determined by society. In order to acquire deeper insight into 'self-determination' and amniocentesis, I will explore how information about amniocentesis causes anxiety.

\section{"Amniocentesis is unnecessary"}

Seven OBs said that they believe it is not necessary to mention amniocentesis except in cases of medically abnormal pregnancy. Dr A reasons in the following manner:

I do not think it is necessary to talk about amniocentesis when not asked...I know the issue of prenatal tests is important and I am specialised in it, but abortion because of anomaly in a foetus occupies a very small portion of all abortion cases. Maybe 100 per year in the whole country... When pregnant women do not ask for it, we do not have to say that actively. Our saying it only causes anxiety.

He reasons that information about amniocentesis does not have to be disseminated because most amniocentesis results are negative. All seven OBs provided this same explanation. There are no official statistics on amniocentesis results, but specialists in amniocentesis explain that some $10 \%$ of pregnant women take amniocentesis. Even in hospitals specialised in amniocentesis, to which women with questionable pregnancies are sent, $10 \%$ of results are positive. It is therefore assumed that private maternity clinics or hospitals not specialised in amniocentesis have even fewer positive results.

Another common explanation concerns the characteristics of amniocentesis. According to Dr E:

Amniocentesis can find only ten percent of all the disorders in a foetus, mainly targeting only Down Syndrome (DS), but patients want to know if the foetus has any anomalies, not only DS. Then what is the use for this test? Except for cases for which amniocentesis is necessary, we do not have to mention it.

These narratives indicate the limitations of amniocentesis. However, if these points are accurately explained to patients over time, patients might not always become anxious. To get more insight into what is happening in actual medical practice in Japan, I now focus on the communication between patients and OBs in order to see 
how anxiety is caused and why. The story of a couple (Mr and Ms B1) is the best case here:

Ms B1: My OB recommended I take the Quattro test to make sure my pregnancy was in good condition. I thought, if a doctor says that, there must be something to make sure of. I did not expect anything bad, I completely believed the test was to confirm that everything was going smoothly. But its result found that it was more than 80 percent likely that my child would have DS. Since then, my husband and I were in total confusion...Then my $O B$ mentioned amniocentesis, but I could not calmly think of it, because it then required us to think of abortion. But I took the test because my OB said so. The result of amniocentesis turned out to be negative. In retrospect, I do not understand what all those events were...I thought that every pregnant woman takes these tests, but I learned later that it was not true. All these tests only confused us, destroying the pregnancy period.

Mr B1: Why did we have to suffer all this? I believed in the doctor's words that it was to make sure the pregnancy was going smoothly, but on the contrary, I had so many sleepless nights. Our OB told me that we could phone him if we had questions, but we couldn't because we knew that he was busy.

MK: Did you think of having a counselling session?

Mr B1: No. Is there such a system? I wish I could have talked freely to someone professional.

The couple obviously experienced anxiety because of the prenatal tests. Why and where did the anxiety come from?

First, the couple uncritically believed their OB's words. They thought the test must be necessary because their $O B$ mentioned it. They also believed that it was to reassure them that the pregnancy was proceeding normally. If they had thought that the Quattro test could logically be followed by the difficult questions of whether to undertake amniocentesis and even whether to terminate the pregnancy, they could have avoided this confusion to some extent.

Second, it is possible to observe casualness in the OB's words, ie, "the test is to hear good news". This statement is probably based on the OB's clinical experience of most test results being negative; this is not only an incomplete truth but even false information. Because of the OB's 'optimistic' statement, Mr and Ms B1 did not critically think about the test's meaning and its result came as a shock. I have already discussed why patients tend to uncritically believe their OBs. Why do some OBs make such casual statements? Issues such as 'lack of time' in their medical practice and 'OB self-image' will be analysed later.

From his own clinical experiences, Satô says that if it is emphasised that the test is performed on all pregnant women, then patients tend to think that having a delivery without knowing the condition of the foetus is not a wise or responsible attitude for would-be parents. ${ }^{7}$ I can state here that one of the characteristics of patient behaviour 
in Japan is to "try to do as much as others do", a tendency that is palpable in the story of Mr and Ms B1. During interviews, I often came across statements such as: "I asked my OB what others usually do [Mina san dôshitemasuka?]". OBs also described patients as being most concerned about "what others do". Anxiety is also caused by not knowing what others do concerning amniocentesis and from a fear of deviating from the norm.

\section{Patient-doctor relationship observed in Mr and Ms B1's case}

Mr B1's comment that he and his partner could not call the OB with their worries because the $\mathrm{OB}$ was busy shows that patients do not take access to information for granted. Despite the fact that their confusion was partly caused by the OB's casualness, the $\mathrm{OB}$, for both $\mathrm{Mr}$ and $\mathrm{Ms} \mathrm{B1}$, still remains an authority to be respected and is not to be disturbed or easily accessed. From Ms B1's repetition of such statements as "because doctors said it" and "I trusted the OB, but feel as if I was betrayed", I could observe that even after all the confusion, she maintained her belief in the absolute correctness of OBs. Some OBs say that they provide information to patients only when asked, but this case shows that the patient does not easily pose questions.

\section{On anxiety}

It is not that knowing about amniocentesis causes anxiety; it is that not knowing enough about amniocentesis that causes anxiety. The Japanese scholar of nursing Tsukamoto argues that "dependence on social norms and environment is proportionate to insufficiency of information". ${ }^{8}$ She also argues that patients' uncertainty about their final decisions is a sign that they have insufficient information. ${ }^{9}$ Of course, in any society, when individuals make decisions, they take their environment into account in one way or another. Moreover, when it comes to information, the concept of sufficiency is relative in each case. Patient uncertainty and confusion in the decision-making process show that the information they receive about amniocentesis is insufficient.

OBs say they do not disseminate information because they want to respect 'selfdetermination', but does this attitude really always enhance a patient's 'selfdetermination'? To consider this question, I present the story of Ms T, who was five months pregnant when I interviewed her. Owing to her age of 37 years, she learned about amniocentesis directly from her OB. Her age made her anxious about her pregnancy and she investigated amniocentesis further using the Internet, where she learned that amniocentesis sometimes leads to abortion because of the abnormalities the test identifies and thus persuade the patient to abort; that the test cannot detect all disorders; and that a negative test result is no guarantee of a healthy child. Moreover, she learned about a government-sponsored financial support system for families with a disabled child, and about a network of parents with DS children that would keep her from being left alone. She says: 
I collected as much information as possible. Even at work, I was using the Internet. I focused on advantages and disadvantages of amniocentesis...I found that amniocentesis often targets DS. Then I read a book about DS. I found that they can express their emotions such as affection, so I thought that I can accept a child even with DS. I finally decided not to take the test.

Ms T was still pregnant at the time of interview, but on the basis of the information about both advantages and disadvantages, she appeared quite sure of her decision not to take the test. I came across other patients who also felt at peace with their decisions and in all these cases the patients themselves had gathered information via the Internet, books and OBs.

Why is the information Ms T sought out on her own not automatically provided to the majority of patients by OBs? 'Lack of time' is a significant factor. According to MHWL research, a majority of patients, $43 \%$, receive a diagnosis within three to ten minutes, while $17 \%$ are diagnosed in less than three minutes. ${ }^{10}$ The number of OBs is decreasing, ${ }^{11}$ and thus the average OB's working hours is increasing and the time they have available to diagnose is decreasing. Some OBs clearly state that "taking time to explain amniocentesis reduces the time for diagnosis, so I do not explain"; or "I decide what is good for my patients to know. There is no time to practise informed consent". ${ }^{12}$ Amniocentesis requires thorough explanation because it includes issues of terminating or continuing pregnancy, but because they lack time OBs often do not broach the subject. Or, in some cases, OBs are casually optimistic, as in $\mathrm{Mr}$ and Ms B1's case.

Counselling sessions would solve these problems, but individuals are not accustomed to the practice of counselling sessions, and as a result Japan's counselling system is under-developed. Dr H says: "There is hardly any idea among the general public that counselling sessions are worth paying money for. Just 'talking' about it is not considered to be a diagnosis in Japan. And if money is not involved in running the counselling system, the system will not sustain itself". Given this reality, there is no time for sufficient explanation, let alone counselling. For these reasons, a patient either does not hear about amniocentesis at all or briefly hears about it, which sometimes causes anxiety.

\section{OB self-images}

Next I analyse, in the context of their own self-images, why OBs do not initiate communication about amniocentesis with patients. Four OBs (4/11) recognise their initial role to "get rid of individuals' anxiety". Dr I and Dr J, who are specialists in prenatal diagnosis and clinical genetics, had this to say:

Dr I: My role is first to listen to the story of a patient and figure out what the problem is. Then I consider if prenatal diagnosis should be mentioned and, if so, what. What I say depends on the problem of each pregnant woman, and my purpose is to consider how to help the pregnant woman feel at ease. 
Dr J: What is common among those pregnant women who want to talk more with me is the fact that they have anxiety [about pregnancy in general]. The content and causes of anxiety differ. So my task is to help them eliminate their anxiety. If after hearing their story I think information about amniocentesis might help the patient to get rid of anxiety, then I talk about it.

In this way, doctors acknowledge that one of their roles is to alleviate the anxiety of pregnant women. If OBs consider that providing information about amniocentesis is a source of anxiety, then they do not talk about it. But if OBs think the same information might help alleviate patients' anxiety, then they provide it.

Mr and Ms B1 assumed their OB intended the test as confirmation of the healthy state of their pregnancy. The same positive statement is motivated by the OB's concern not to scare patients.

In the next section, I will further explore ideas about 'self-determination' and amniocentesis in Japan's history of eugenics.

\section{"Is DS so bad as to warrant abortion?"}

Six of the eleven doctors said they do not inform patients about amniocentesis because they doubt that DS should be a target of selective abortion.

Dr B: If you talk about amniocentesis, it mainly means DS in the current situation. But I have to wonder if $D S$ is really so bad. Therefore, I do not actively try to find Nuchal Translucency ('NT' hereafter) in a foetus either.

Dr F: I do not think that children with DS should be aborted. To begin with, there is no notion in Japan that foetuses with DS must be screened.

With his statement "there is no notion in Japan that foetuses with DS must be screened," Dr F makes it seem as though discrimination against people with DS does not exist in Japan. This is not the case. Amniocentesis specialists stated that more than 80 percent of cases with positive results are aborted, ${ }^{13}$ which indicates that a foetal anomaly, such as DS, has crucial influence on any given patient's decision whether or not to continue a pregnancy. In order to better understand OB attitudes, I will summarise the history of eugenics in Japan.

The National Eugenic Law was created in 1940 and revised as the Eugenic Protection Law in 1948. These laws were concerned with "preventing the birth of inferior descendants" $" 14$ and articulated legal procedures to sterilise people with certain disorders. In order to re-build the Japanese society after the Second World War, the government was interested in preventing the birth of "economically unproductive people" or those with a handicap. Some 16,000 people were sterilised between 1949 and 1994 in the name of "eugenic operation", 15 and women were targeted to a greater 
extent than men. In the beginning of the 1970s, in line with a rise of a number of social movements, groups of disabled people and women started openly criticising this law, and, in combination with objections raised during the 1994 International Conference on Population and Development, this led to the law being revised in 1996 with the introduction of the Law to Protect the Mother's Body, in which all articles regarding eugenic operation were deleted. The law currently contains legal indications for abortion, which does not include selective abortion. ${ }^{16}$ Since the 1970 s, there have been governmental attempts to introduce a selective abortion clause (amniocentesis was introduced in Japan in 1968), but these have always been opposed by the same groups of disabled and women, who have called it "eugenics practised by the state", and such a clause has never been enacted. Over 30 years of public debate has essentially transformed 'amniocentesis' into a euphemism for 'eugenics'.

OBs are well aware of this history. Social stigma associated with amniocentesis has created a belief that it should not be openly practised, and doctors' statements reflect their desire not to become "a promoter of eugenic thoughts". As Dr B says:

Disabled groups have visited medical associations several times to protest the attempt to introduce the selective abortion clause. This is also why doctors do not want to openly talk about it. You never know who will tell whom what if we promote the test at all.

Similarly, most OBs cited the mass media in their explanations of why they do not want to talk about amniocentesis. According to Dr K:

I think pregnant women should be informed of amniocentesis as one alternative, and I used to provide information about it to pregnant women. Then the media would come to interview me. I don't know if they do it purposefully or not, but now I know they have an agenda to scandalise me as a cruel medical doctor who eradicates handicapped people. They pick apart some convenient sentences from me to fit their scenario, take my picture. I am shocked and fed up.

Thus Dr K no longer accepts interviews from mass media but remains silent in public when it comes to the issue of amniocentesis.

\section{Legal conditions for selective abortion}

In Japan, abortion is legal in cases where pregnancy is the result of sexual assault, or when the economic position of the would-be parents is so grave that it would endanger the child. Sexual assault is not easy to prove, thus more than 90 percent of abortions, including selective abortions, are justified, at least officially, on economic grounds. Strictly speaking, selective abortion is not legal, and this fact influences medical doctors as well. Dr A says:

As a specialist in prenatal diagnosis, I must say that this area is on very shaky ground. If someone with authority wants to destroy this field, it can be done in no time. They only have to regulate the 


\section{application of the economic reasons clause. I am always scared} actually.

As discussed, the selective abortion clause will likely never be introduced in Japan and selective abortion will continue to be practised under the economic reasons clause. Given this legal situation, OBs do not openly practise prenatal diagnosis of selective abortion. It makes doctors cautious of what they say and do regarding amniocentesis.

Explanations provided so far for $\mathrm{OB}$ silence about amniocentesis are often linked to the principle of 'self-determination', both at the level of the individual medical practice and in public debate. In medical practice, the OB believes: "If I mention the test, they will feel forced. This would impede their practice of self-determination". In other cases, OBs explain that although many patients ask them what they would do in their position, they answer, "I don't know, you have to decide on your own", calling that decision "self-determination". At the public level, both the state and social organisations hold that "if OBs mention the test, patients feel forced into the test and that impedes the individual's practice of self-determination, thus doctors do not have to mention it." OBs are also afraid that they might lead patients toward eugenic practices or an illegal act by referring to amniocenteses.

Why do OBs equate their silence - or non-intervention - with respect for 'selfdetermination'? What theoretical logic can be found to justify this link? In the next section, I address this question by looking at sub-concepts of 'self-determination' and at how the concept was originally formed.

\section{Theoretical consideration of the principle 'self-determination'}

The origin of the term 'self-determination' can be traced back to the concept of 'individual autonomy' in J. S. Mill's On Liberty. ${ }^{17}$ The concept of 'individual autonomy' holds that "a man is responsible only for those of his actions that influence others. Regarding matters that influence only himself, he is absolutely independent. In other words, he is the absolute sovereign of his own mind and body". ${ }^{18}$ This way of conceptualising individual autonomy arose because of the assumption that "the individual's independence is under constant threat from other (equally self-serving) individuals", ${ }^{19}$ because every individual tries to maximise his gain. Thus individuals are expected to be "self-sufficient and independent". ${ }^{20}$ In this way, "there has been a gradual alignment of autonomy with individualism". 21

In the Nuremberg Code of 1947, the medical concept of 'self-determination' was wedded to the concept of informed consent. The Code articulated that "medical intervention ought to be done under the consent of the patient and the consent ought to be based on the patient's motivation, comprehension and his own choice". ${ }^{22}$

According to the main points of the above explanation, medical self-determination can be delineated as follows: Because medical practice is primarily concerned with the proper moral conduct of health-care providers, including medical doctors, examination of the requirements of autonomy is directed at the actions that such 
providers ought to take to "avoid interference with or constraint of patients' autonomy". ${ }^{23}$ Thus within bioethics, "the requirement to respect autonomy is understood as the duty of medical doctors to identify those patients who have capacity for choice, in terms of developmental criteria and the absence of psychological pathology", ${ }^{24}$ and "to offer those patients choices concerning their health care and the information necessary to make an informed choice; and to respect the free, informed choices they make". ${ }^{25}$

There are a number of arguments on 'self', 'autonomy' and 'self-determination', but it would be possible to contend that the following three points are sub-concepts of 'autonomous self' ${ }^{26}: 1$ ) voluntary motivation (to acquire necessary information to make a final decision); 2) (capacity for) comprehension of the situation and choice; and 3) non-intervention. In light of these explanations, how can we observe the practice of 'self-determination' in Japan?

\section{Analysis of Japan in light of theoretical explanation of 'self-determination'}

In analysing patients' attitudes based on the above three sub-concepts, I want to consider 'voluntary motivation', because neither 'capacity' nor 'non-intervention' is relevant without a self that wants to take advantage of both and do what only the self can do: decide.

Considering that patients often do not know about the test or do not even ask about amniocentesis, it appears that patients are not motivated to acquire information. Is this their choice? Where does this behaviour come from? According to my observations, the problem is that patients do not even know where to begin to gather information. I will explain.

First, patients associate a 'taboo' with the term 'gene', especially as it relates to 'heredity', or 'iden'. The Japanese bioethicist Takebe mentions that the term iden is avoided in every sphere of Japanese society, including in educational and medical practice, because of the stigma it carries: the term iden itself is almost equated with eugenics and to talk about it can sound offensive to others. ${ }^{27}$ Takebe's research also shows that when a patient desires a genetic test to determine heredity, he or she chooses a hospital at least one hour away by train, because people are afraid of meeting their acquaintances at local hospitals. ${ }^{28}$ Interviews with patients also show that a majority want to believe that they are not affected by heritable illness, and to avoid talking about genetic inheritance is sometimes a way to affirm that they are 'healthy'. Thus not talking about iden is not necessarily the patient's choice; rather he or she is afraid of being stigmatised by talking about it. I would suggest that a patient who feels such uncertainty under the pressure of a social taboo cannot be described as 'autonomous'.

One more example provides deeper insight into the patient-doctor relationship.

Research by the Japanese clinical geneticist and paediatrician Watanabe and medical geneticist Shimada shows that even students at medical schools are confused about basic concepts in clinical genetics, such as the differences between inherited disease 
and diseases caused by genetic disorders, and those between hereditary and chromosomal disorders. ${ }^{29}$ In reality, even some OBs who are not specialised in amniocentesis do not always know exactly how to explain genetic inheritance or amniocentesis. There have been some attempts to set up counselling systems in some hospitals and some do indeed exist, but if a patient wants to raise a question about iden at all, the social setting, even within medical institutions, is not equipped to listen. Imagine the 'interaction' in such a patient-doctor relationship: a decision made based on an interaction between a patient who does not know what or where to ask about genetic inheritance, and an $\mathrm{OB}$ who passively answers any questions the patient manages to pose - is this 'self-determination'? It's not surprising that the 'interaction' between patients and doctors is largely silent.

A second reason patients lack voluntary motivation to seek information relates to their autonomy to 'maximise their gain'. Originally, the concept of autonomous self grew out of individualism, because of the presumption that the self's independence is under constant threat from others. But the narratives of individual patients reveal that they actually want to be much the same as everyone else. In other words, in this case, their "maximizing the gain' means "to be like others" and "not to be deviant". At the same time, in order to 'maximise their gain', many patients uncritically follow their OB's advice. I often found this attitude among my interviewees; I would easily find it in much of Japan as well.

It should be noted that for many patients the OB's participation and the advice of others are part of their 'decision-making'; as in Mr Z's case, even when only following the OB's advice, they think they are deciding on their own.

Not all patients are quiet and obedient; some make demands of their OBs. Yet the excessively demanding patients and the silently obedient ones are similar in one crucial respect: both are dependent on OBs. Dr H, who is one of the most experienced in amniocentesis in Japan, says:

Patients ask us to look closely at the condition of the foetus. So we take more time in ultrasound. Then they get angry, saying it is too long. Now, if we take less time and fail to find something, they get angry. They think that we are perfectly skilful and make no mistakes!

Dr H continues:

On the issue of amniocentesis, both patients and medical doctors are wrong. Clients should be responsible for their decisions instead of excessively leaning on OBs. OBs are also only reacting to the needs of clients, passively. Both are avoiding taking responsibility.

Then where does the gap between theory and practice of 'self-determination' come from? I conclude this paper by considering this question, shedding light on the meaning of 'self' observed in my field research. 


\section{Conclusion}

Regarding the 'self' of patients as autonomous does not explain their decision-making concerning amniocentesis in Japan, as they seem to be lacking in knowledge and the self-motivation to acquire any. Instead, patients often uncritically follow OB advice and what others do. There are a number of discussions about the concept of 'autonomy' that I do not recount here, but at the least I can say that patients, who do not know even when, let alone how, to pose a question, cannot be defined as autonomous. In light of the explanation of the principle of 'self-determination', 'nonintervention' is only one of its three (or more) sub-concepts. Therefore, merely not interfering in a patient's decision-making process is not fulfilling a condition of 'selfdetermination'. It seems that misunderstanding the concept of 'self-determination' in medical practice is caused by OBs' mixing two subtly different concepts about self and autonomy. Those two concepts must be discerned: medical doctors trying to identify autonomy in patients is different from doctors assuming that patients are already autonomous. My field research shows that OBs treat patients as if they were already autonomous, which means that OBs do not intervene and treat patients as if they already have sufficient information and know what to ask and what to do with information about medical treatment.

Furthermore, in light of the origin behind 'self-determination', OB 'non-intervention' makes sense only when patients' voluntary decision-making capacity is threatened. Originally, the concept of self-determination emerged to prevent authority from suppressing the choices of patients. My field research shows that patients are indeed oppressed, but not by the action of authority as much as by its inaction. Only in that sense is patient decision-making capacity threatened. Patients actually need support from $\mathrm{OBs}$ as a source of information.

These misunderstandings emerge because the term 'self-determination' is so widely and popularly used that its meaning is not accurately examined. The concept is often understood simply as if it means 'decision-making without intervention'. At the same time, 'self' is often misunderstood as isolated in nature, as not interacting with its environment. Those employed in medical practice need to accurately understand the meaning of self-determination, especially regarding the interaction between a patient and his or her environment - which includes doctors. Academia, meanwhile, needs to build arguments on the concept of 'self' that implies more than 'an isolated self'.

How can patients become 'wiser'? Given the limited time of diagnosis and shortage of medical doctors, efforts to establish a genetic counselling system are required as a matter of course. But it must be noted that taboos surrounding genetic information, which are prevalent in Japan, are playing a critical role in preventing individuals from knowing about genetics and even from visiting genetic counselling, if any is available. Education reforms in this field are certainly necessary. Provision of more information in medical practice is key as well, in a way that helps patients understand their own medical treatments. Some groups of genetic nurses and counsellors are trying to spread the concept of 'wise patients' by introducing counselling systems. ${ }^{30}$ Perhaps these attempts will enhance patient consciousness and independence in the future. In 
this regard, this author does not agree with the argument of the 1999 state guideline on blood marker test, ${ }^{31}$ or the Society of Gynaecology and Obstetrics, ${ }^{32}$ that "a medical doctor does not have to inform patients of prenatal test not should the doctor recommend the test to clients... because it is difficult for patients to go against what a doctor says". ${ }^{33}$ This author does not contend that pregnant women should undergo amniocentesis, but that their decision as to whether or not to take the test should be based on knowledge and thinking it over themselves. As it is, most do not take the test, because they do not know about it.

Critics might argue that Japanese society is not ready to provide information about amniocentesis because patients will only feel obliged to submit to the test. But my field work shows that sufficient knowledge encouraged some patients to decide on their own and to be confident in their decision. Knowledge rather empowered them: they became confident in their decision-making and thus in their future.

Reproductive genetic technologies develop whether one likes it or not. In the long run, hiding information will discourage individual autonomy. One does not have to acquire information about technologies or genetics if he or she does not want to do so, of course. But even the decision not to do so is based on one's awareness.

\section{Acknowledgement}

I thank Dr N. Arimori at St. Luka's College of Nursing for her generous support during my fieldwork in Japan.

\footnotetext{
${ }^{1}$ The International Institute for Asian Studies, P.O.Box 9515, 2300 RA Leiden, The Netherlands m.kato@let.leidenuniv.nl

${ }^{2}$ Gakkô kihon chôsa, The Ministry of Education, Culture, Sport, Science and Technology, http://www.mext.go.jp/b_menu///////////shingi/chukyo/chukyo4/gijiroku/015/07012325/001/001.pdf.

${ }^{3}$ The second committee meeting of the Ministry of Health and Welfare (MHW) on the use of the blood marker test; 6. http://www1.mhlw.go.jp/shingi/s9812/txt/s1209-1_18.txt.

${ }^{4}$ Satô, Kôdô. 1999. Shusseizen shindan: Inochi no hinshitukanri e no keishô. Yûhikaku sensho, Tokyo: 68-69.

${ }^{5}$ For the history of genetic counselling system in Japan, see: Takebe, Hiraku. 1992, Genetic counselling and informed consent, http://www.eubios.info/HGR/HGRHT.htm. For dilemmas of genetic counselling, see, for example, Kanazawa, Ichiro 1993 Diagnosis and genetic counselling for Huntington's disease http://eubios.info/IND/INDIK.htm.

${ }^{6}$ Satô, op. cit. note 4, pp.74-75.

${ }^{7}$ Ibid

${ }^{8}$ Tsukamoto, Yasuko. 2005. Iryô no naka no ishi kettei - Shusseizen shindan: Yôsuikensa o ukeru ninpu tachi, Kôchi shobô. Tokyo: 50.

${ }^{9}$ Tsukamoto, op. cit. note 8, pp.51.

${ }^{10}$ The Ministry of Health and Welfare. 1998. http://www.jcoa.gr.jp/content/zuryou.html: 2.

${ }^{11}$ According to research by the Japanese Red Cross Society, 67 of 92 Red Cross hospitals in Japan are short of medical doctors. Amongst all the departments, Ob/Gyn and Paediatrics have the most serious problems. (Seikyo Shimbun, 29 May, 2006)

12 Takebe, Hiraku. 2002. Hitogenomu ni miru kôshi mondai. In Kagakugijutsu to kôkyôsei, by Sasaki Tsuyoshi \& Kim Tae Chang. Tokyo daigaku shuppankai: 238.

${ }^{13}$ Tsukamoto, op. cit. note 8, pp.45.
} 
${ }^{14}$ The first sentence of the Eugenic Protection Law.

${ }^{15}$ The Asahi Shimbun. 14 February 1996. Yûseihogohôkaisei tashiba no sa. Tokyo.

${ }^{16}$ For the English version of the law, see: Kato, Masae. 2005. Women's rights?: Social movements, abortion and eugenics in modern Japan. PhD dissertation at Leiden University: 290-291. For the debate about the law, see Ashino, Yuriko. Reproductive health rights: The present situation of Japan and its problems. http://wom-jp.org/j/REPORT/repro.html.

${ }^{17}$ Hanazaki, Kôhei and Takashi Kawamoto. Jikoketteiken to wa nanika. Gendai shisô 1998; 26-8: 44. ${ }^{18}$ Ibid

${ }^{19}$ Code, L. 2000. The prevention of autonomy and the subjection of women: Discourse of social advocacy at century's end. In Relational autonomy: Feminist perspectives on autonomy, agency and the social self. C. Mackenzie and N. Stoljar, eds. Oxford University Press. New York and Oxford: 6. ${ }^{20}$ Ibid

${ }^{21}$ Ibid

${ }^{22}$ On the transformation of the concept of informed consent, see R.R. Faden and T.L. Beauchamp. Informed consent - Kanja no sentaku. Misuzu shobô 1994; pp. 4-5, 53 \& 68. On the Nuremberg Code, see Code, op. cit. note 19, pp.77-78.

${ }^{23}$ Dodds, S. 2000. Choice and control in feminist bioethics. In Relational autonomy: Feminist perspectives on autonomy, agency and the social self. C. Mackenzie and N. Stoljar, eds. Oxford University Press, New York and Oxford: 216.

${ }^{24}$ Ibid

${ }^{25}$ Ibid

${ }^{26}$ Faden and Beauchamp, op. cit. note 22 , pp.186-218.

${ }^{27}$ During his lecture at The International Institute for Asian Studies (IIAS), the Netherlands, 5 September 2006.

${ }^{28}$ Takebe, op. cit. note 12, p.221.

${ }^{29}$ Watanabe Atsushi and Takashi Shimada. Igakubugakusei o taishô to shita rinshôiden ni kansuru rikaidochôsa - Igakubu ni okeru rinshôidenkyôiku no hitsuyôsei. Igaku kyôiku 2005; 36 (4): 235.

Takebe, op. cit. note 12, p.231.

${ }^{30}$ Arimori, Naoko. Idenkango to wa? Josan Zasshi 2005; 59 (2): 117-122.

${ }^{31}$ MHW, 21 July, 1999. http://homepage2.nifty.com/ganesh/marker.html.

${ }^{32}$ The society was established in 1949, and currently has 15,900 members. Members are not necessarily medical doctors. As a society with professionals, they have influence on the content of guidelines, policies and sometimes laws in the field of gynaecology and obstetrics.

${ }^{33} \mathrm{http} / / / \mathrm{www}$ 1.mhlw.go.jp/houdou/1107/h0721-1_18.html. Translated into English by the author. 